\title{
High Power Combline Filter for Deep Space Applications
}

\author{
A. V. G. Subramanyam, ${ }^{1}$ D. Siva Reddy, ${ }^{1}$ V. K. Hariharan, ${ }^{1}$ \\ V. V. Srinivasan, ${ }^{1}$ and Ajay Chakrabarty ${ }^{2}$ \\ ${ }^{1}$ ISRO Satellite Centre (ISAC), Bangalore 560017, India \\ ${ }^{2}$ Department of Electronics and Electrical Communications Engineering, Indian Institute of Technology (IIT), Kharagpur 721302, India
}

Correspondence should be addressed to A. V. G. Subramanyam; avgsub@isac.gov.in

Received 6 May 2014; Revised 3 July 2014; Accepted 25 July 2014; Published 14 September 2014

Academic Editor: Mirco Raffetto

Copyright (C) 2014 A. V. G. Subramanyam et al. This is an open access article distributed under the Creative Commons Attribution License, which permits unrestricted use, distribution, and reproduction in any medium, provided the original work is properly cited.

\begin{abstract}
An S-band, compact, high power filter, for use in the Mars Orbiter Mission (MOM) of Indian Space Research Organization (ISRO), has been designed and tested for multipaction. The telemetry, tracking, and commanding (TT\&C) transponder of MOM is required to handle continuous RF power of $200 \mathrm{~W}$ in the telemetry path besides simultaneously maintaining an isolation of greater than $145 \mathrm{dBc}$ to its sensitive telecommand path. This is accomplished with the help of a complex diplexer, requiring high power, high rejection transmit path filter, and a low power receive path filter. To reduce the complexity in the multipaction-free design and testing, the transmit path filter of the diplexer is split into a low rejection filter integral to the diplexer and an external high rejection filter. This paper highlights the design and space qualification phases of this high rejection filter. Multipaction test results with $6 \mathrm{~dB}$ margin are also presented. Major concerns of this filter design are isolation, insertion loss, and multipaction. Mission performance of the on-board filter is normal.
\end{abstract}

\section{Introduction}

Telemetry, tracking, and commanding (TT\&C) transponder in a spacecraft meant for deep space mission requires a high power (100 s of watts) transmitter, a high sensitive ( $135 \mathrm{dBm})$ receiver, and respective high gain antenna systems. Since both the transmitter and receiver require similar antenna systems, it will be highly taxing in terms of on-board weight and volume, if we use two antennas independently. It is economical to use a common antenna system for both uplink and downlink, with the help of a diplexer [1]. Diplexer is a passive component that connects the common antenna feed, simultaneously, to both transmitter and receiver with proper isolation. It consists of a high power transmit filter, a receive filter, and a combining network as shown in Figure 1.

Multipactor [2] is an electron resonance phenomenon which occurs at radio frequencies in high power components like filters and resonators and transmission lines operating in vacuum. It represents a possible payload failure mechanism for communications satellites since it can destroy microwave components or transmission lines, or it can significantly raise noise levels [3]. Multipactor effect has been known for many years; it still presents a critical problem and more constraints in satellite communication system applications in terms of transmit power, number of carriers, and wider bandwidth. Multipactor occurs whenever the electrons are sufficiently energized by the RF waves; they are driven back into a surface and secondary electrons are produced. The effective secondary electron yield depends on the impact energy and angle of incidence, the surface properties, and the direction of the RF field at the time of impact [4]. Under certain conditions, the phase of the secondary electrons remains locked with the RF field driving the impacts, so that secondary electron emissions tend to be in phase with the applied RF field resulting in multiplication of the electrons. This finally results in reducing the power output of the component and increasing its return loss.

Main aim of this paper is to prevent multipaction breakdown in the transmitter path and also realize the hardware in compact size and lesser weight. This paper highlights the intricacies involved in the design, realization, and space qualification of the high power transmit filter, in a short time, 


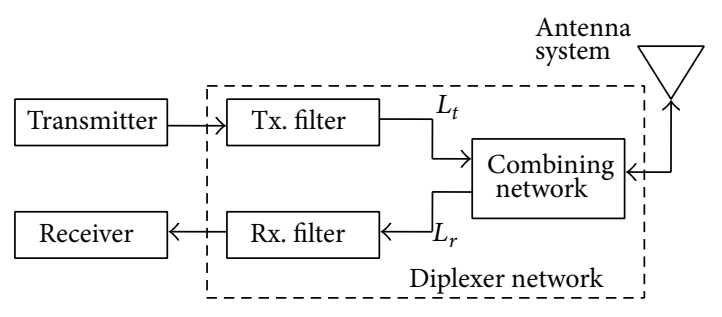

FIgURE 1: TT\&C system configuration of a spacecraft.

for a deep space mission requirement. Simulated and measured performances of the filter are presented. Multipaction analysis and test results are also discussed.

\section{High Power Filter Design, Multipaction Analysis, and Fabrication}

2.1. Design and Optimization. The primary purpose of the high power filter is to suppress the receiver band frequency spurious coming from the TWTA amplifier and pass the transmit band RF signal with minimum loss. It is required to provide an isolation of at least $120 \mathrm{dBc}$ to the receive signal and thereby it will aid in simplifying the diplexer design by sharing the rejection requirement. Otherwise the diplexer alone has to provide this higher isolation $(>145 \mathrm{dBc})$ for the receive signal, which increases its design, realization, and testing complexity.

The filter design also aims at achieving the required performance in a compact and low weight system. Accordingly suitable design-cum-fabrication techniques and material reduction were also implemented.

Compact implementation of filtering structures for space applications [5] is based on evanescent mode waveguides, whose typical configuration using symmetrical metal ridges is as shown in Figure 2. These filters, originally proposed in $[6,7]$ and refined in [8], are essentially composed of a hollow, below cut-off waveguide housing, which transmits the energy between standard waveguide access ports through shunt capacitive elements (ridges). The below cut-off waveguide sections placed between consecutive ridges can be modeled as impedance inverters and shunt inductances that, when combined with the cited capacitances, provide the required filter resonances. Evanescent mode filters are a good choice for the input and output stages of satellite payloads, since they can provide moderate bandwidth responses with excellent out-of-band performance and sharp selectivity. In addition these filters are very competitive in terms of mass and volume due to their below cut-off waveguide housing [9-11].

Initially, when the MOM system was evolving, independent polarizations for uplink and downlink were planned and there was no necessity for a diplexer. To meet these requirements, specifications for the high power filter were derived as in Table 1, for which a 12-pole double-side ridged waveguide filter (F1) was designed. Based on [12], a rigorous field theory description of the ridge waveguide is utilized to formulate the modal scattering matrix of the waveguide-toridge-waveguide discontinuity, which is the basic building
TABLE 1: Required specification and simulated results of the ridged guide filter-F1.

\begin{tabular}{lc}
\hline Parameter & Requirement \\
\hline Carrier frequencies $(\mathrm{MHz})$ & 2217 \\
$1 \mathrm{~dB}$ bandwidth $(\mathrm{MHz})$ & 2231 \\
Rejection $(\mathrm{dB})$ & 100 \\
{$[@ 2041$ \& 2054 MHz] } & $145 \mathrm{~min}$. \\
Insertion loss $(\mathrm{dB})$ & 0.7 max. \\
Return loss $(\mathrm{dB})$ & $15 \mathrm{~min}$. \\
Power handling requirement $(\mathrm{W}) \mathrm{CW}$ & $225(53.52 \mathrm{dBm})$ min. \\
I/O interface & Quarter height WR340 \\
\hline
\end{tabular}

block in the design. Also with the help of Fritz Arndt's Wasp-Net Software [5], the ridged waveguide filter integrated with the quarter height waveguide to double-side ridged waveguide transitions was designed and overall optimization was carried out. Figure 2 shows the structure of the filter-F1 and its simulated response.

Simulated response on HFSS was meeting all the required electrical specifications (rejection of $154 \mathrm{dBc}$ ), including power handling, and has the cross section as $35 \mathrm{~mm} \times 35 \mathrm{~mm}$ with the overall length as $622 \mathrm{~mm}$. It is easy to fabricate this filter into two symmetric halves and assemblies. But the sensitivity analysis shows that this structure is vulnerable to fabrication tolerances and after fabrication the scope for tuning is very remote. For this structure, small perturbations in the penetration depths of the upper and lower metal insert seriously affect the ridge gap dimension, which is identified to be very sensitive parameter. Additionally, slight misalignments can easily spoil the required symmetry of this filter design. Hence this filter-F1 was not fabricated.

To overcome such drawbacks, a potential alternative consisting of an asymmetrical configuration, with metal inserts placed only in one wall of the waveguide housing [13], a combline based structure, filter-F2, is planned as shown in Figure 4. Combline resonator is a hybrid structure where a coaxial transmission line is formed by a partial height post in series with a gap capacitor placed in a rectangular or circular cavity. Combline cavities use a below cut-off waveguide structure and hence are small compared to their counter parts in normal propagating waveguide structures.

Unlike the traditional comb-line filter, which has no metallic obstacle between resonators, this filter employs rectangular cavities with coupling slots. This further reduces resonator lengths and thereby the overall filter length. This structure yields a somewhat higher unloaded quality factor because more of the field is enclosed. The coupling between resonators is controlled via the width of the slot, which in turn control the bandwidth of the filter.

Relatively this structure has better symmetry in the skirt response and the required rejection could be met with eleven resonators $[14,15]$. The cavity size/dimension is decided by the centre frequency and spurious suppression response of the filter. To realize the given filter specifications in an iriscoupled combline structure, the transmission and reflection 


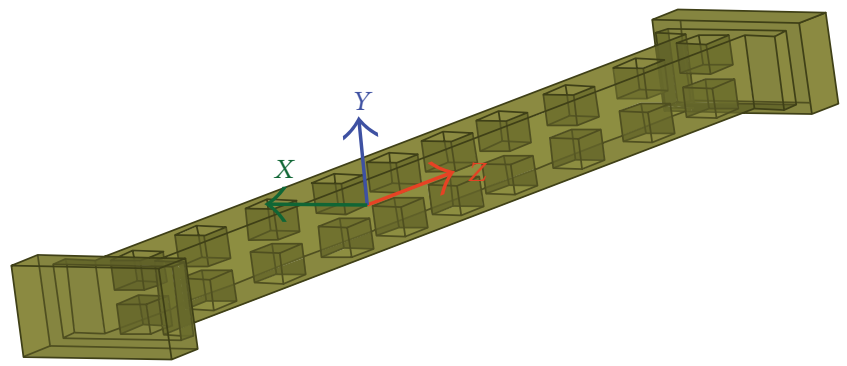

(a)

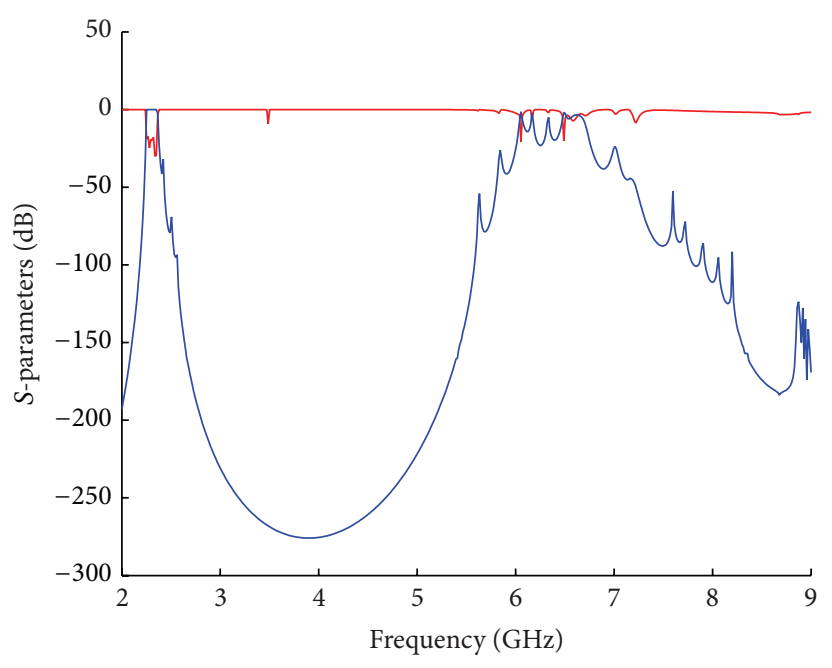

(b)

FIGURE 2: Double-side ridged waveguide filter-F1 and its simulated response.

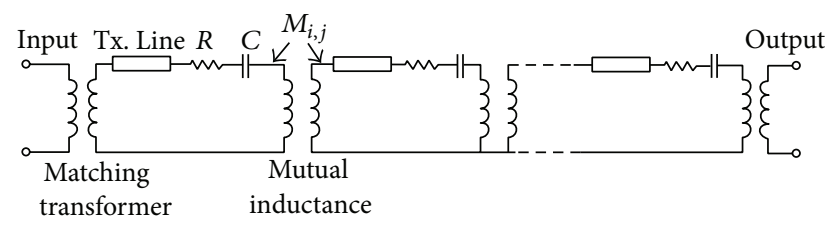

FIGURE 3: Equivalent circuit of the iris-coupled combline filter.

parameters of Chebyschev transfer function and the coupling coefficient matrix $K_{i, j}$ from the low-pass prototype elements $[14,16]$ are determined. Using these values, the parameters of the equivalent circuit shown in Figure 3 can be calculated [1].

This type of iris-coupled combline filters is also presented recently in [1]. The basic structure of the present filter is the same as that in [1], that is, iris-coupled combline filters, usually meant for low power applications but intended for high power satellite applications. Hence the equivalent circuits are the same except for the input/output interface (here quarter height waveguide interface instead of coaxial interface). Similarly, multipactor analysis is also based on the resonator voltages that are obtained from $3 \mathrm{D}$ simulators like HFSS.

In this circuit, the resonators are represented by transmission lines, short-circuited at one end, in series with a lumped capacitor. The iris-coupling between the resonators is inductive and is modeled by a mutual inductance; the input/output coupling to the filter is also inductive and is modeled by an ideal transformer. This transformer matches the quarter height guide of WR340 to the combline guide of $35 \mathrm{~mm}$ by $32 \mathrm{~mm}$. The insertion loss of the filter is represented by a resistor in series with the lumped capacitor.

The transmission-line (Tx. Line) parameters are characteristic impedance $Z_{0}$ and electrical length $\theta$ at the center frequency $f_{c}$. At the resonant frequency, the series capacitance $C$ will be

$$
C=\frac{1}{2 \pi f_{c} Z_{0} \tan \theta} .
$$

Reactance slope parameter $X$ for this resonator is given by [1]

$$
X=\frac{Z_{0}}{2}\left[\theta(1+\tan \theta)^{2}+\tan \theta\right] .
$$

In this equation, the electrical length $\theta$ is expressed in radians. The mutual inductances $M_{i, j}$ are related to coupling coefficients $K_{i, j}$, the reactance slope parameter $X$, and the frequency $f_{c}$ by

$$
M_{i, j}=2 \pi f_{c} X K_{i, j} .
$$

The simulated $S$-parameter response of this 11-pole filterF2 is as shown in Figure 4. The structure is optimized using library elements based Wasp-Net software [5] and verified in HFSS software [17] before fabrication.

The power handling of combline filter is limited by the gap capacitance formed between the resonator open end and ground plane where the electric field has its maximum intensity [1]. This gap is typically a small fraction of the wavelength, making it susceptible to corona or multipaction. Due to this reason combline filters are usually not used for high power applications. However [1] shows one way of designing (dielectric filling), whereas this paper shows the other simple and easy way (increasing critical gap) at the design stage, by which the power handling capability can be increased still maintaining the combline performance.

Overall length of the present filter-F2, structure got reduced to almost $450 \mathrm{~mm}$ and the cavity cross-sectional dimension, with lots of trials, has been finalized to be $35 \mathrm{~mm}$ $\times 32 \mathrm{~mm}$ for the optimum performance. Due to impedance mismatch, these optimum dimensions cannot be directly interfaced with the preceding and succeeding sections that carry high RF powers. Waveguide routing on both sides of the filter-F2 are of standard WR 340 with reduced height (86.36 $\times 10.8 \mathrm{~mm}^{2}$ ), to save on weight and volume. To match the filter impedance to the rest of the routing, suitable impedance transformers were designed and attached on either side. The simulated filter-F2 transmission loss and return loss response shown in Figure 4 includes that of the transformer also. 


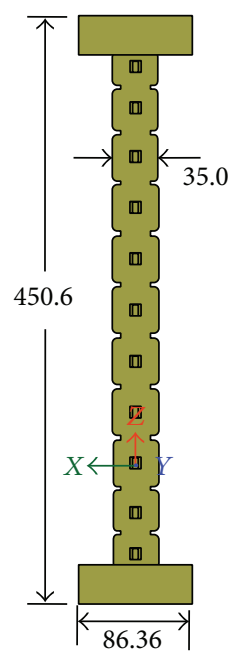

(a)

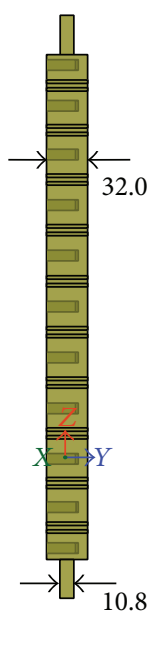

0.8

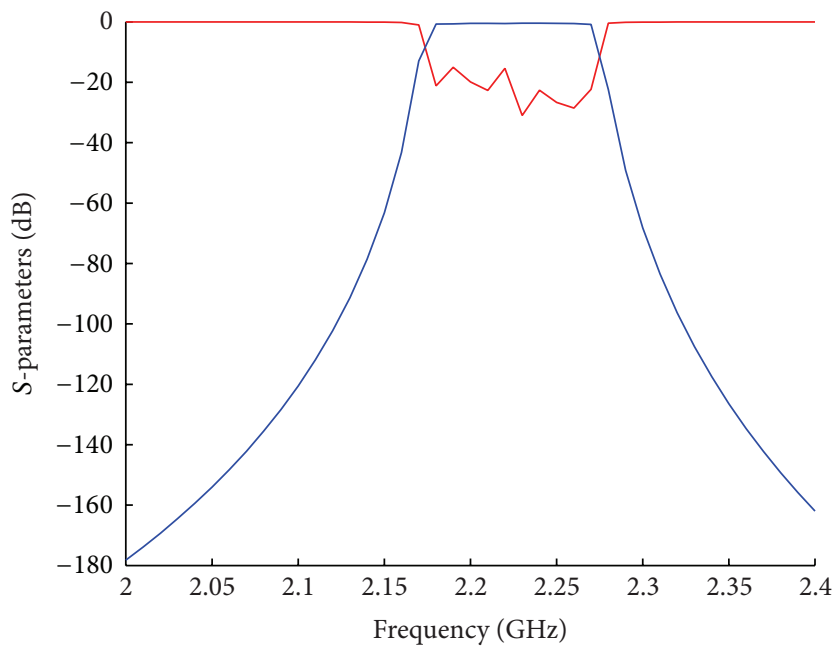

(b)

FIGURE 4: The structure and response of 11-pole iris-coupled combline filter-F2.

In an attempt to increase the power handling capability of the filter-F2, the field pattern was studied using HFSS. It is found that the peak values of field are concentrated near the sharp edges of the posts towards the grounding planes. These sharp edges were rounded off with $1 \mathrm{~mm}$ radius and field pattern is observed again. It is noted that rounding of these edges improved the power handling of the filter by $57 \%$. Hence this technique was adopted in all later versions of the filter design.

At the time of loading this filter-F2 for fabrication, TT\&C frequencies of the mission got changed. Also to exercise the option of launch support from external agencies (outside India) a single polarization scheme for both uplink and downlink was adopted, which needs a diplexer to separate transmit and receive signals with proper isolation. Therefore a complex diplexer has to be designed to provide the required rejection of $>145 \mathrm{dBc}$ between the high power transmit and high sensitive receive channels.

The design complexity of the diplexer is shared by designing a simple diplexer with about $40 \mathrm{dBc}$ rejection and a high power filter in tandem for the rest of the rejection requirements. With this requirement a new set of specifications for the high power filter (F3) were derived as enumerated in Table 4. Meanwhile the 11-pole filter-F2 that got fabricated was taken up as qualification model (QM) for all stringent tests including high power tests, at initial TT\&C frequencies.

For the new specifications of Table 4, a filter design with 10 -pole Chebyschev polynomial and $0.01 \mathrm{~dB}$ ripple in the pass-band was chosen. These filter-F3 characteristics have been realized using a similar combline structure with iris coupling and impedance transformers (see (1)-(3)), without tuning elements. Size of the filter-F3 is the same as the previous one and the overall length is reduced to just $374 \mathrm{~mm}$, as in Figure 5. Its simulated response is shown in Figure 6.

2.2. Multipactor Analysis. Estimation of multipactor threshold for this combline structure-F3 is based on the procedure given in [1]. The voltages of each resonator of the high power filter-F3 were calculated using HFSS model and $200 \mathrm{~W}$ of rms input power. This is achieved from the $3 \mathrm{D}$ model of the filter using HFSS "field calculator" and by drawing "polyline" at the point of field calculation; the absolute value of peak resonator can be evaluated for the respective resonators. These are reported in Table 2 at centre frequency for both filters F2 and F3, which also shows the input voltage $V_{\text {in }}$ corresponding to $P_{\text {in }}=200 \mathrm{~W}$ rms input power and the voltage magnification factors (VMFs). $V_{\text {in }}$ is calculated from

$$
V_{\text {in }}=\left(2 \times 50 \times P_{\text {in }}\right)^{1 / 2}=141.4 \mathrm{~V} .
$$

It can be noted that maximum peak voltage is built up in the 6 th resonator for $\mathrm{F} 3$.

After determining the voltages of the combline resonators, multipaction safety margin can be calculated for different gaps using multipactor threshold voltage $V_{M}$ given by [18]

$$
V_{M}=63 * f * d,
$$

where frequency $f$ is in $\mathrm{GHz}$ and gap $d$ is in millimeters.

Filters are silver plated inside and hence, in the above equation, the slope of $63 \mathrm{~V} /(\mathrm{GHz} \cdot \mathrm{mm})$ for silver has been used. Safety margin for the multipaction can be calculated from

$$
\operatorname{Margin}=20 \times \log \left(\frac{V_{M}}{V_{r}}\right) .
$$

Table 3 shows the computed multipaction margins for both filters F2 and F3. The analysis is based on the parallel plate model and does not take into account the quality of the plating process in multipaction breakdown. However it can be used to determine the indicative multipaction thresholds and not the exact values. The critical gap area of the combline filter, between the resonator post open end and top cover, 
TABLE 2: Calculation of voltage magnification factor (VMF) for filters F2 and F3.

\begin{tabular}{|c|c|c|c|c|c|}
\hline \multirow{2}{*}{ Resonator Number } & \multirow{2}{*}{ Peak input voltage, $V_{\text {in }}$} & \multicolumn{2}{|c|}{ Peak resonator voltage, $V_{r}$} & \multicolumn{2}{|c|}{ VMF } \\
\hline & & $\mathrm{F} 2$ & F3 & F2 & F3 \\
\hline 1 & 141.4 & 973 & 911 & 6.88 & 6.44 \\
\hline 2 & 141.4 & 1169 & 1317 & 8.27 & 9.31 \\
\hline 3 & 141.4 & 1480 & 1331 & 10.47 & 9.41 \\
\hline 4 & 141.4 & 1274 & 1412 & 9.01 & 9.98 \\
\hline 5 & 141.4 & 1509 & 1326 & 10.67 & 9.38 \\
\hline 6 & 141.4 & 1286 & 1420 & 9.09 & 10.04 \\
\hline 7 & 141.4 & 1479 & 1293 & 10.46 & 9.14 \\
\hline 8 & 141.4 & 1265 & 1399 & 8.95 & 9.89 \\
\hline 9 & 141.4 & 1417 & 1184 & 10.02 & 8.37 \\
\hline 10 & 141.4 & 1150 & 939 & 8.13 & 6.64 \\
\hline 11 & 141.4 & 913 & - & 6.46 & - \\
\hline
\end{tabular}
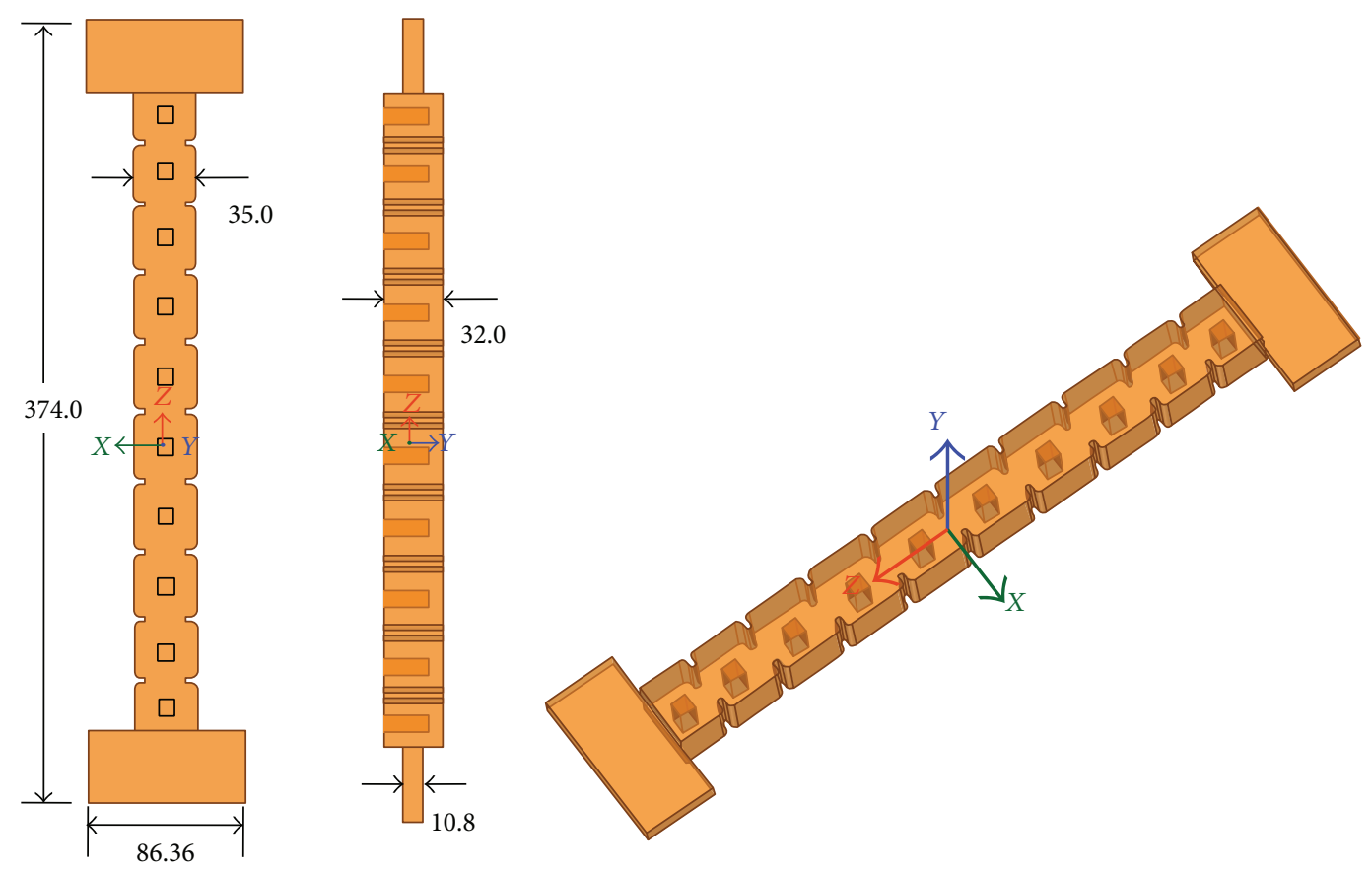

FIGURE 5: Different views of the final filter-F3 configuration with internal dimensions.

is far from infinite parallel plate. In fact the aspect ratio of the gap (height/length) is $>1$. Therefore it is expected that multipactor threshold will be higher than the values calculated, due to significant fringing fields in the region [1].

From Table 3, though filter F2 consists of tuning screws for RF optimization purposes, here in the computations, these are not taken into account. It is observed that the worst case margin for $\mathrm{F} 2$ is $-3.58 \mathrm{~dB}$, which is poorer by more than $1 \mathrm{~dB}$. As tuning elements were introduced in the case of F2, the critical gap between the post and top wall further reduces, resulting in multipactor margins worse than those computed in Table 3. In spite of the above negative margins, the filter-F2 has demonstrated more than $3 \mathrm{~dB}$ margin (measured); further, to achieve the required ECSS
$6 \mathrm{~dB}$ margin, drastic physical changes such as increasing the gaps/size are not warranted due to the restricted physical constraints (component size).

In contrast, as the multipaction margins for F3 are not worrisome (worst case margin is $-2.1 \mathrm{~dB}$ only), it necessitates multipaction testing for higher power levels. Hence even with little negative margins (highly approximated) for the multipactor, we have proceeded for the fabrication of this new filter F3 and could achieve the required result.

2.3. Fabrication. Filter is fabricated by milling a block of space grade Aluminum alloy 6061. The adopted mechanical design as shown in the assembly drawing of Figure 7 gives better mechanical stability and environmental protection. 
TABLE 3: Estimation of multipaction margin for filters F2 and F3.

\begin{tabular}{|c|c|c|c|c|c|c|}
\hline \multirow{2}{*}{ Res. Number } & \multicolumn{2}{|c|}{ Gap (mm) } & \multicolumn{2}{|c|}{$V_{M}$} & \multicolumn{2}{|c|}{ Multipactor margin (dB) } \\
\hline & $\mathrm{F} 2$ & F3 & $\mathrm{F} 2$ & F3 & $\mathrm{F} 2$ & F3 \\
\hline 1 & 7.26 & 7.91 & 1017.7 & 1110.7 & 0.39 & 1.72 \\
\hline 2 & 6.93 & 7.72 & 971.4 & 1083.9 & -1.61 & -1.69 \\
\hline 3 & 7.12 & 7.91 & 998.0 & 1110.6 & -3.42 & -1.57 \\
\hline 4 & 7.13 & 7.94 & 999.4 & 1115.2 & -2.11 & -2.05 \\
\hline 5 & 7.13 & 7.94 & 999.4 & 1115.2 & -3.58 & -1.50 \\
\hline 6 & 7.13 & 7.94 & 999.4 & 1115.2 & -2.19 & -2.10 \\
\hline 7 & 7.13 & 7.94 & 999.4 & 1115.2 & -3.40 & -1.29 \\
\hline 8 & 7.13 & 7.91 & 999.4 & 1110.6 & -2.05 & -2.00 \\
\hline 9 & 7.12 & 7.72 & 998.0 & 1083.9 & -3.04 & -0.77 \\
\hline 10 & 6.93 & 7.91 & 971.4 & 1110.7 & -1.47 & 1.46 \\
\hline 11 & 7.26 & - & 1017.7 & - & 0.94 & - \\
\hline
\end{tabular}

TABLE 4: Specifications and measured parameters of filter F3.

\begin{tabular}{lcc}
\hline Parameters & Specification & Measured \\
\hline Frequency $f_{c}(\mathrm{MHz})$ & 2295.5 & 2295.5 \\
$1 \mathrm{~dB}$ band-width & $100 \mathrm{MHz} \pm 10 \mathrm{MHz}$ & $106 \mathrm{MHz}$ \\
Insertion loss at $f_{c} \pm 10 \mathrm{MHz}$ & $<0.7 \mathrm{~dB}$ & $0.40 \mathrm{~dB}$ \\
Return loss at $f_{c} \pm 10 \mathrm{MHz}$ & $>15 \mathrm{~dB}$ & $23.5 \mathrm{~dB}$ \\
Rejection at Rx band $2114 \pm 10 \mathrm{MHz}$ & $>120 \mathrm{dBc}$ & $141.0 \mathrm{dBc}$ \\
Power handling requirement @2298.48 MHz & $185 \mathrm{~W}$ & $740 \mathrm{~W}(6 \mathrm{~dB}$ margin) \\
I/P \&O/P interface & WR-340 quarter height & WR-340 quarter height \\
\hline
\end{tabular}

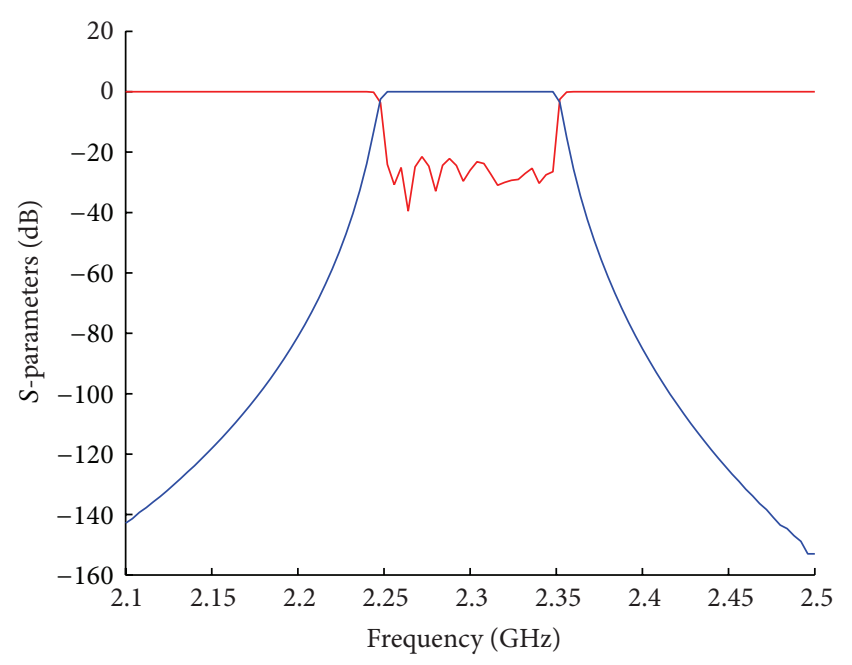

FIGURE 6: Simulated $S$-parameter response of the final filter configuration.

The input and output are interfaced with WR-340 quarter height waveguide. The internal surface of the high power filter has been silver-plated to improve the insertion loss. The photograph of the assembled high power filter is shown in Figure 8. With 200 watts as the input power to this filter, it can dissipate 17.6 watts ( $0.4 \mathrm{~dB}$ max. measured insertion loss) in terms of heat. This input along with its physical dimensions, metallic properties, and the mounting location on the carrier plate were subjected to thermal analysis. Based on the thermal analysis the outer surface of the filter has only been black painted, as it does not generate any considerable amount of heat energy that necessitates any cooling mechanism.

Vent hole requirement was addressed and implemented based on the ESA calculator estimation. For the given volume of the filter eight vent holes of $1.6 \mathrm{~mm}$ diameter are drilled on the input and output interface flanges at appropriate places where there is less possibility for radiation. For the given volume of the structure with eight vent holes it takes roughly $500 \mathrm{sec}$ to completely vent to the level of $10^{-5}$ torr. The filter design also aims at achieving the required performance in a compact and low weight system. Accordingly suitable material reduction and fabrication techniques were also implemented.

\section{Measurements and Environmental Tests}

3.1. PNA Measurements. Figure 9 shows the measured pass band S-parameters of the filter-F3 using Agilent's Precision Network Analyzer (PNA). Similarly Figure 10 shows the typical rejection response of the filter at receive frequency, which reads to be better than $123 \mathrm{dBc}(120 \mathrm{dBc}$ spec.) on PNA. The measured results are listed in Table 4 against the system specifications. All the parameters are comfortably meeting the specifications. Higher bandwidth is considered to achieve lower insertion loss and better margin for multipaction. 


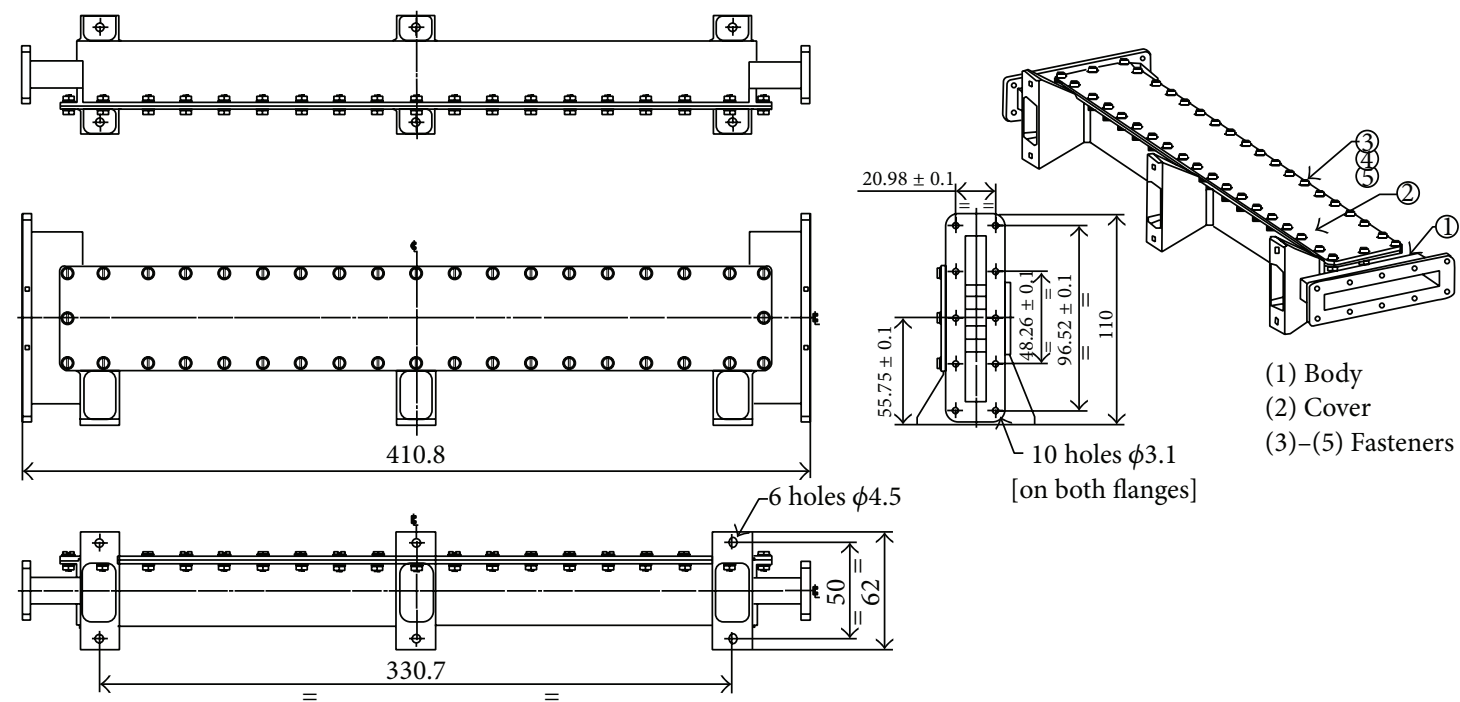

FIGURE 7: Assembly drawing of high power filter.

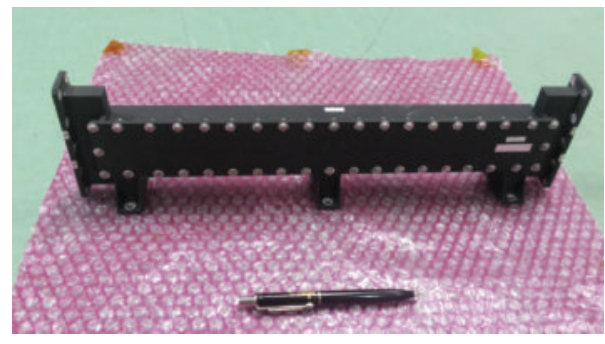

FIGURE 8: Photograph of the high power filter.

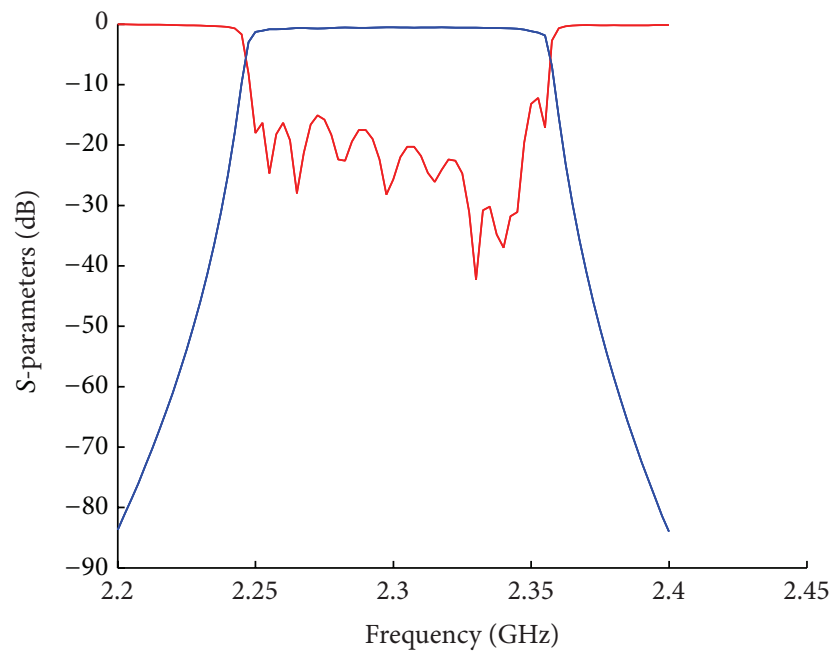

FIGURE 9: Measured pass band response of the filter-F2.

3.2. Rejection Measurements. In fact the rejection of the filter is about $-140 \mathrm{dBc}$ as per simulation. Due to the dynamic range limitation of the PNA, measurement was not feasible to find the actual rejection offered by the filter at receive frequency. To perform this measurement, a high power

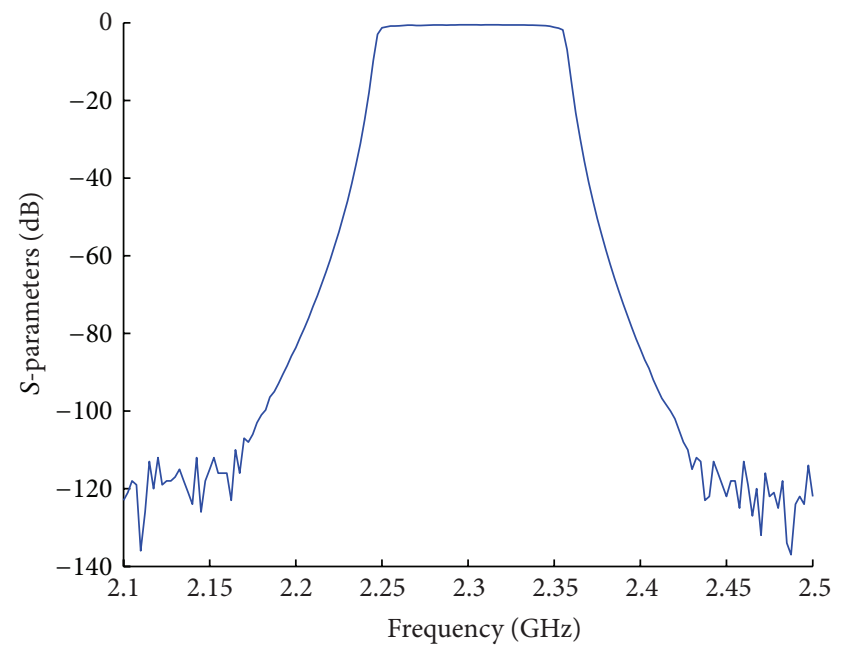

FIGURE 10: Measured out-of-band rejection response of the filter-F2.

source and high dynamic range spectrum analyzer were used. Measurement was carried out at $+47.5 \mathrm{dBm}$ and filter rejection at receive frequency is found to be $141.0 \mathrm{dBc}$.

3.3. RF Characterization with Different Environmental Tests. RF characterization of the filter involves the following tests starting with functional test; they are initial bench test, postpassive thermal cycle test (10 cycles of 1 hour dwell at $-15^{\circ}$ to $+80^{\circ} \mathrm{C}$ ), postvibration test (sine, random vibrations, and mechanical shock at stipulated higher " $g$ " values), and high power test followed by final bench test. In addition, RF characterization of the filter was carried out at the extreme hot $\left(+80^{\circ} \mathrm{C}\right)$ and cold $\left(-15^{\circ} \mathrm{C}\right)$ temperatures, to estimate the shift in filter response due to temperature. During this test, the frequency response has been shifted to higher side almost by $2.0 \mathrm{MHz}$ in cold soak with reference to ambient and 


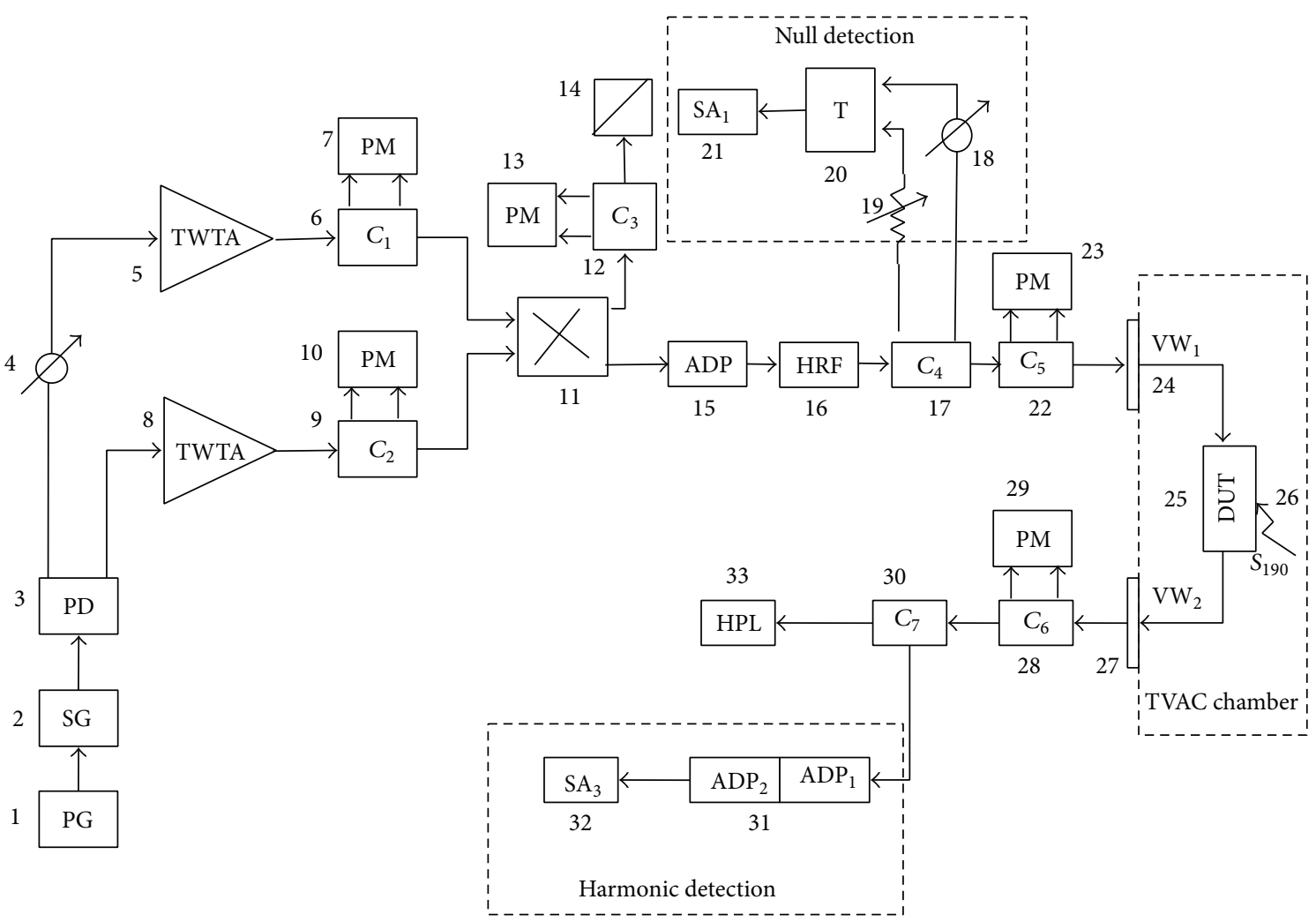

FIGURE 11: Multipaction and power handling test setup.

similarly to lower side almost by $3.0 \mathrm{MHz}$ at hot temperature with reference to ambient. Since the design bandwidth of the filer is high, this minor shift will not affect the overall system performance.

\section{High Power Test Including Multipaction}

The high power test comprises power-handling test and multipaction test at hard vacuum. The block diagram in Figure 11 shows the high power test setup. The serial numbers in the diagram indicate the instrumentation used. In the block diagram, pulse generator (PG) sends pulses to signal generator for modulating the RF carrier. Through power divider (PD) and phase shifter equiphase signals are fed to TWT amplifiers. Outputs of amplifiers are combined in a hybrid/combiner (11) and fed to the DUT that is placed in the thermovacuum chamber (TVAC) through filters. Null detector (ND) is connected in this path. The variable attenuator and the phase shifter in the reflection path were adjusted to achieve a return loss null on Spectrum Analyzer $\left(\mathrm{SA}_{1}\right)$. The DUT output from the TVAC is connected to a high power load after being tapped for the third harmonic detection (THD) on a spectrum analyzer $\left(\mathrm{SA}_{3}\right)$. Forward and reflected signal flow is monitored at various points in the chain using dual directional couplers $(C)$, power meters (PM), and spectrum analyzers (SA).

For electron seeding, a radioactive source is placed next to the filter and directed to the vent holes in the close proximity to the high field region. Almost the same setup

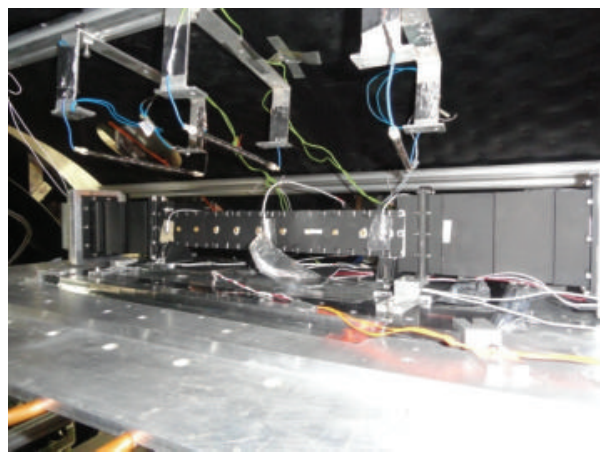

FIGURE 12: Filter-F2 inside TVAC chamber with associated components for the multipaction test.

is used for both power handling and multipaction tests of the filter, except that the power handling test is done with CW RF power (from a single TWTA) whereas multipaction test is done with pulsed power. The setup consists of two mechanisms for detecting the onset of multipaction, namely, null detection and third harmonic detection. Simultaneous observation of abnormality in both the detectors confirms the occurrence of multipaction.

To validate the test setup, an $S$-band gap-sample is used and multipaction is simultaneously detected on both the third harmonic and null detectors as shown in Figure 13. Figure 12 shows the photograph of the filter-F2 mounted 

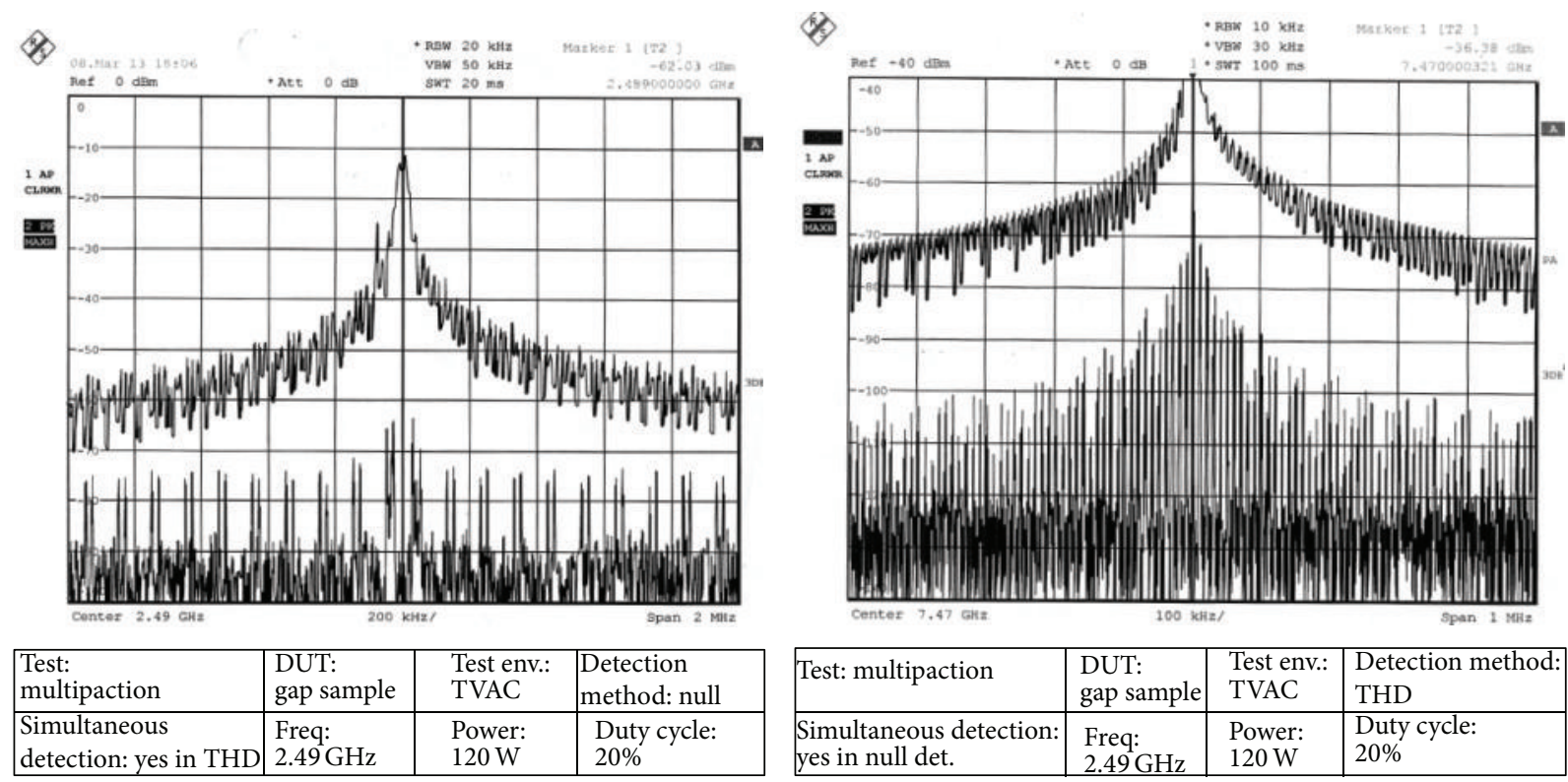

FIGURE 13: Gap-sample test for validating multipaction test setup.

inside thermovacuum (TVAC) chamber along with IR lamps, thermal sensors, waveguide transitions, and so forth.

A vacuum bake-out at $+85^{\circ} \mathrm{C}$ for $12 \mathrm{hr}$ was performed prior to multipaction test to prevent out-gassing. Initially the high power test has been carried out on the filterF2 which has been designed at old TT\&C frequencies $(2217 \& 2231 \mathrm{MHz})$. The package has successfully completed the power handling test with nominal power $(250 \mathrm{~W})$ for 12 hours. But it has failed during multipaction test at RF input power level of $420 \mathrm{~W}$. The corresponding null detector and third harmonic plots are shown in Figure 14. Subsequently one more Qualification Model Filter-F3 has been planned and developed exactly at MOM frequencies (identical to flight model).

Reasons for the failure of the filter-F2 were thoroughly studied. (a) Critical dimensions and gaps were measured and ensured that the new design had better margins, (b) tuning elements might have introduced critical gaps with dissimilar metal junctions and hence were avoided in new design, and (c) extra precaution in maintaining cleanliness and handling was adopted in addition to regular procedures. Final power reaching at the input of the filter-F3 is estimated to be $185 \mathrm{~W}$ after considering the actual TWTA output and en route on-board losses. Subsequent to basic characterization and vacuum-baking, the new filter-F3 is subjected to power-handling test at nominal power $(200 \mathrm{~W})$ for 6 hrs duration at extreme hot temperature $\left(+80^{\circ} \mathrm{C}\right)$. The multipaction test has been carried out, at the same elevated temperature, initially at $50 \mathrm{~W}$ of RF power and then slowly peak power is increased to $100,200,370,600$, and then $740 \mathrm{~W}$.

The intermediate test data after a few minutes dwell, for lower power levels, and 1-hr dwell period for $370 \mathrm{~W}$ ( $3 \mathrm{~dB}$ margin) and $740 \mathrm{~W}$ (6 dB margin), are recorded using printer connected to spectrum analyzers. Temperature variation at three points on the DUT is continuously monitored during the test and found to be within limits. No abnormalities in the detectors are observed, confirming nonoccurrence of multipaction event. The new filter-F3 has successfully completed the multipaction test and paved the way for realizing the flight model. The corresponding high power test plots of the detectors are shown in Figure 15. On the same lines main and redundant flight model filters were realized and flown successfully with the spacecraft.

\section{Conclusion}

Filter design is aimed at meeting the primary specifications for multipaction, insertion loss, rejection, mass, and size. Accordingly the number of sections, cavity cross section, and other parameters were optimized to meet the primary specifications. This resulted in a pass band bandwidth of about $100 \mathrm{MHz}$. This also caters to cover both the main and redundant frequencies in transmit/receive bands, dispersion due to temperature, and fabrication tolerances. This higher bandwidth helped (1) to reduce the insertion loss and (2) to extend the multipaction threshold margin to higher powers. The disadvantage of the increased bandwidth lies in the increased number of sections for the same rejection and thereby physical length. But the disadvantage of having lesser bandwidth is that it requires loose coupling between adjacent resonators which demands more spacing between them and thereby increases the overall filter length. In light of these points, a trade-off bandwidth of $100 \mathrm{MHz}$ for the designs is chosen.

To take care of high power problems, especially after the failure of the first component, several additional precautions were implemented including the regular steps, most of which are summarized as increasing the critical gaps, avoiding tuning screws, avoiding dissimilar metal joints and uniform 

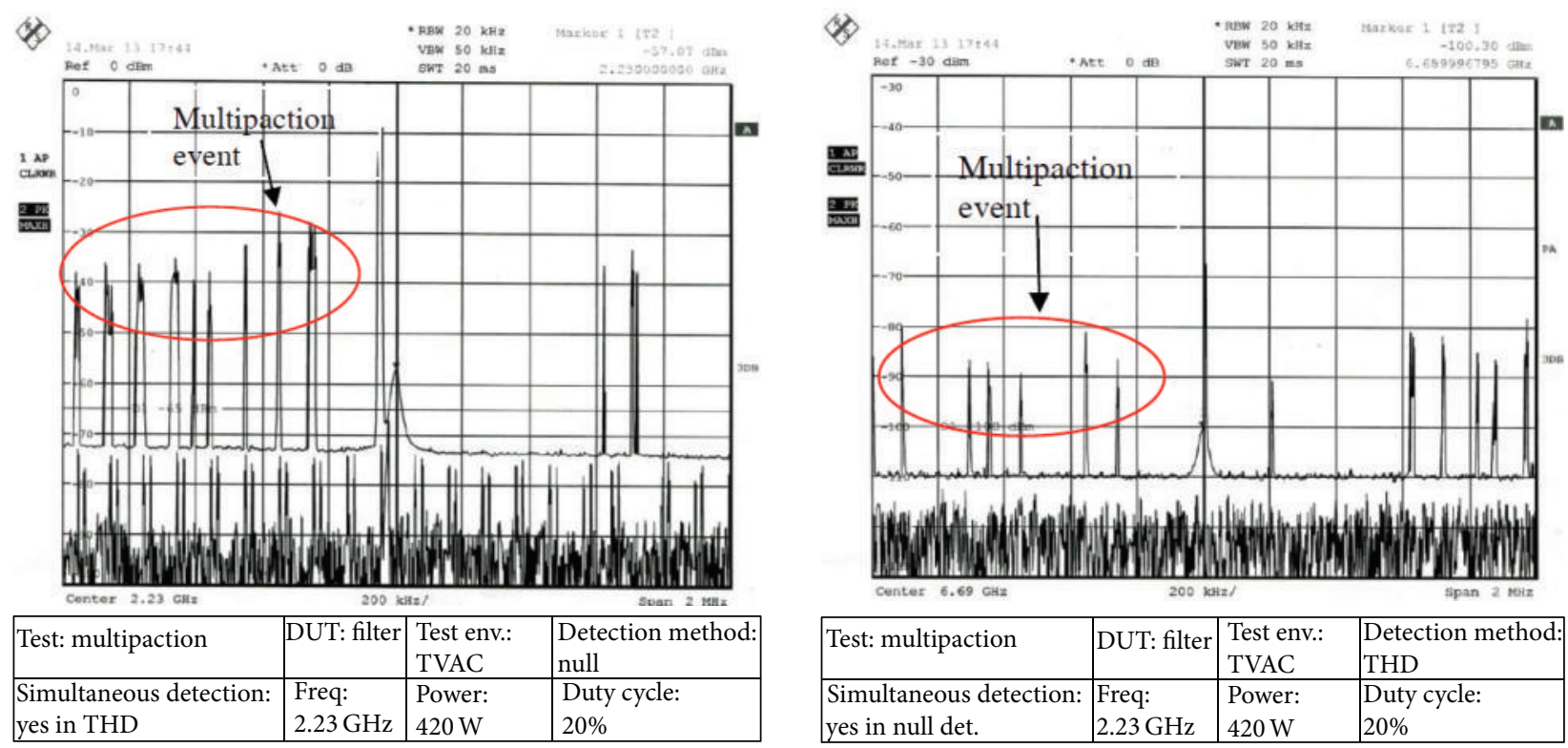

FIGURE 14: Multipaction test on high power filter-F2.
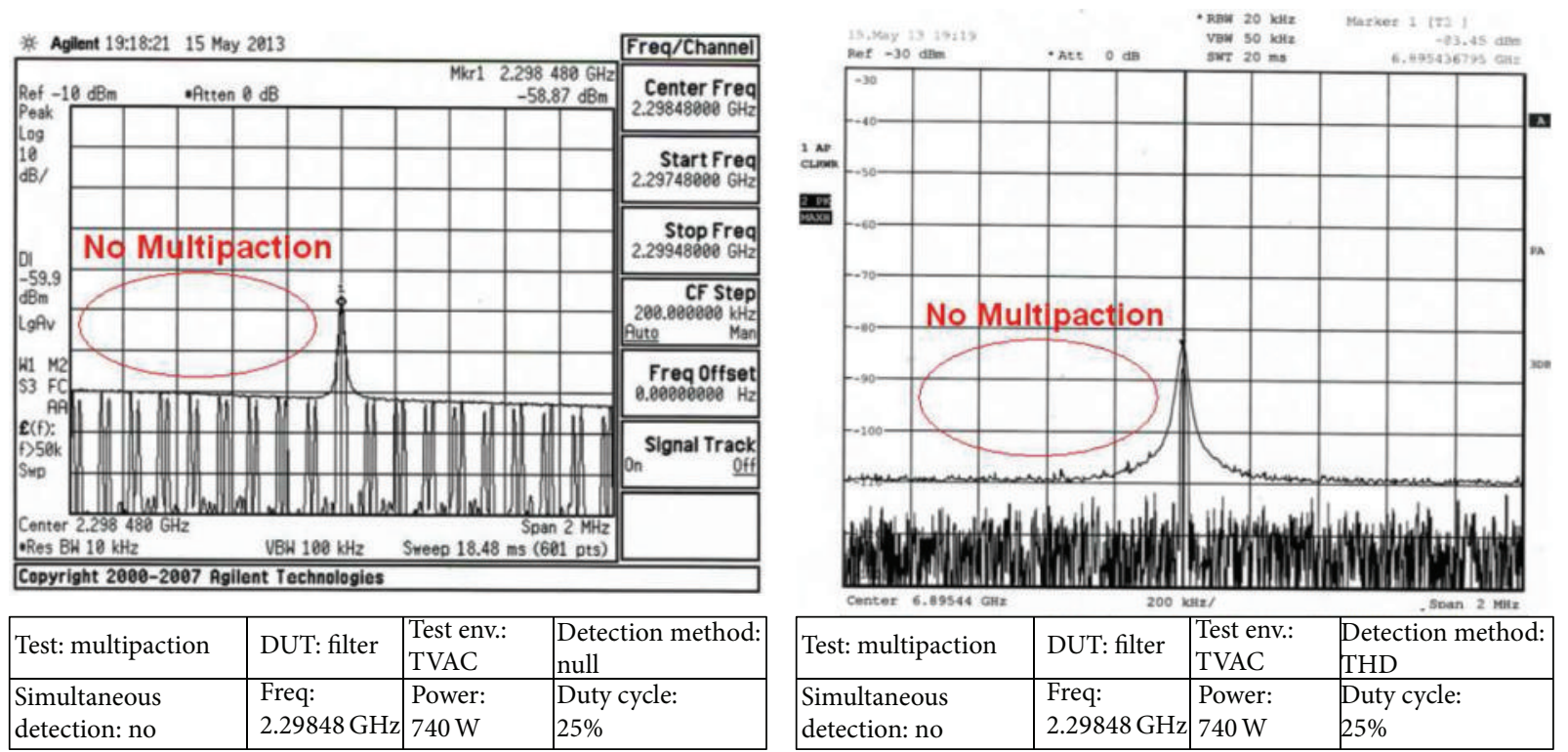

FIGURE 15: Successful multipaction test @ $740 \mathrm{~W}$ on the final filter-F3.

silver-plating the inner surface, proper matching at the input/output, rounding off the sharp edges, providing vent holes, using black paint on the outer surface for better thermal control, and last but not least maintaining cleanliness and proper handling of the filter throughout the developmental stages. After successful tests the high power filter is integrated with the spacecraft and flown. Presently, its on-board mission performance, in deep space en-route Mars orbit, is normal and is providing seamless communication link to ground stations on the Earth.

\section{Conflict of Interests}

The authors declare that there is no conflict of interests regarding the publication of this paper.

\section{Acknowledgments}

Authors thank Mr. K. Krishnamoorthy and Mr. K. M. Subramanyam, Mechanical section, ISAC, for their meticulous planning and fabrication of the component in short time 
and Dr. V. Vamsi Krishna, Passive Systems Section, ISAC, for his support in measurements and helpful discussions. Authors also thank Mr. H. K. Arora and his team of Space Application Centre, Ahmedabad, for their timely cooperation and support in Multipaction testing.

\section{References}

[1] K. Shamsaifar, T. Rodriguez, and J. Haas, "High-power combline diplexer for space," IEEE Transactions on Microwave Theory and Techniques, vol. 61, no. 5, pp. 1850-1860, 2013.

[2] J. R. M. Vaughan, “Multipactor," IEEE Transactions on Electron Devices, vol. 35, no. 7, pp. 1172-1180, 1988.

[3] N. Rozario, H. F. Lenzing, K. F. Reardon, M. S. Zarro, and C. G. Baran, "Investigation of Telstar 4 spacecraft Ku-band and Cband antenna components for multipactor breakdown," IEEE Transactions on Microwave Theory and Techniques, vol. 42, no. 4, pp. 558-564, 1994.

[4] S. Riyopoulos, D. Chemin, and D. Dialetis, "Effect of random secondary delay times and emission velocities in electron multipactors," IEEE Transactions on Electron Devices, vol. 44, no. 3, pp. 489-497, 1997.

[5] F. Arndt, WASP-NET Software, MiG GmbH \& Co.KG, Bremen, Germany, 1996-2011.

[6] G. F. Craven, "Waveguide Bandpass Filters using evanescent modes," Electronics Letters, vol. 2, no. 7, pp. 251-252, 1966.

[7] G. F. Craven and C. K. Mok, "The design of evanescent mode waveguide bandpass filters for a prescribed insertion loss characteristic," IEEE Transactions on Microwave Theory and Techniques, vol. 19, no. 3, pp. 295-308, 1971.

[8] R. V. Snyder, "New application of e vanescent mode waveguide to filter design," IEEE Transactions on Microwave Theory and Techniques, vol. 25, no. 12, pp. 1013-1020, 1977.

[9] R. V. Snyder, "Broadband waveguide filters with wide stopbands using a stepped-wall evanescent mode approach," in Proceedings of the IEEE MTT-S International Microwave Symposium Digest, pp. 151-153, Boston, Mass, USA, 1983.

[10] C. K. Mok, "Design of evanescent-mode waveguide diplexers," IEEE Transactions on Microwave Theory and Techniques, vol. 21, no. 1, pp. 43-48, 1973.

[11] R. Levy, H. W. Yaos, and K. A. Zaki, "Transitional combline/ evanescent mode microwave filters," in Proceedings of the IEEE MTT-S International Microwave Symposium Digest, pp. 461464, April 1996.

[12] J. Bornemann and F. Arndt, "Transverse resonance, standing wave, and resonator formulations of the ridge waveguide eigen value problem and its application to the design of E-plane finned waveguide filters," IEEE Transactions on Microwave Theory and Techniques, vol. 38, no. 8, pp. 1104-1113, 1990.

[13] V. E. Boria and B. Gimeno, "Waveguide filters for satellites," IEEE Microwave Magazine, vol. 8, no. 5, pp. 60-70, 2007.

[14] G. Matthaei, L. Young, and E. M. T. Jones, Microwave Filters, Impedance-Matching Networks, and Coupling Structures, Artech House, Dedham, Mass, USA, 1980.

[15] R. Levy, R. V. Snyder, and G. Matthaei, "Design of microwave filters," IEEE Transactions on Microwave Theory and Techniques, vol. 50, no. 3, pp. 783-793, 2002.

[16] G. Craven and R. Skedd, Evanescent Mode Microwave Components, Artech House, 1989.
[17] High Frequency Structure Simulator-HFSS, M/s Ansoft, Atlanta, Ga, USA, 2002.

[18] ESA/ESTEC Multipactor Calculator, ver. 1.6, April 2007. 

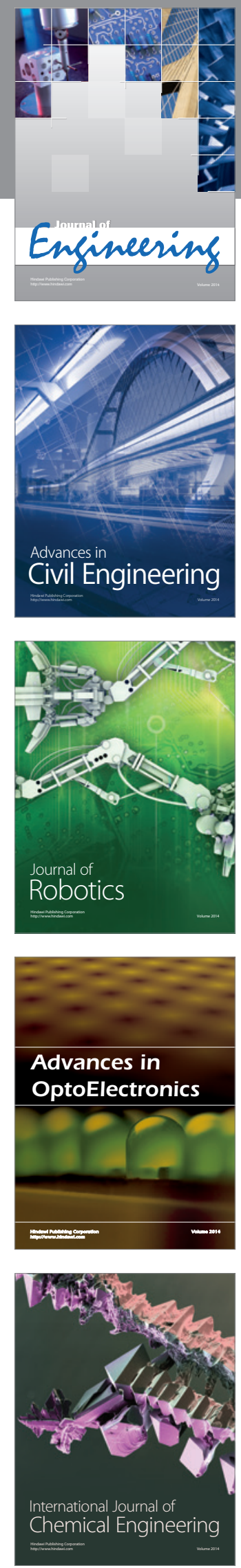

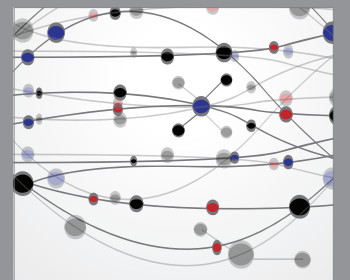

The Scientific World Journal
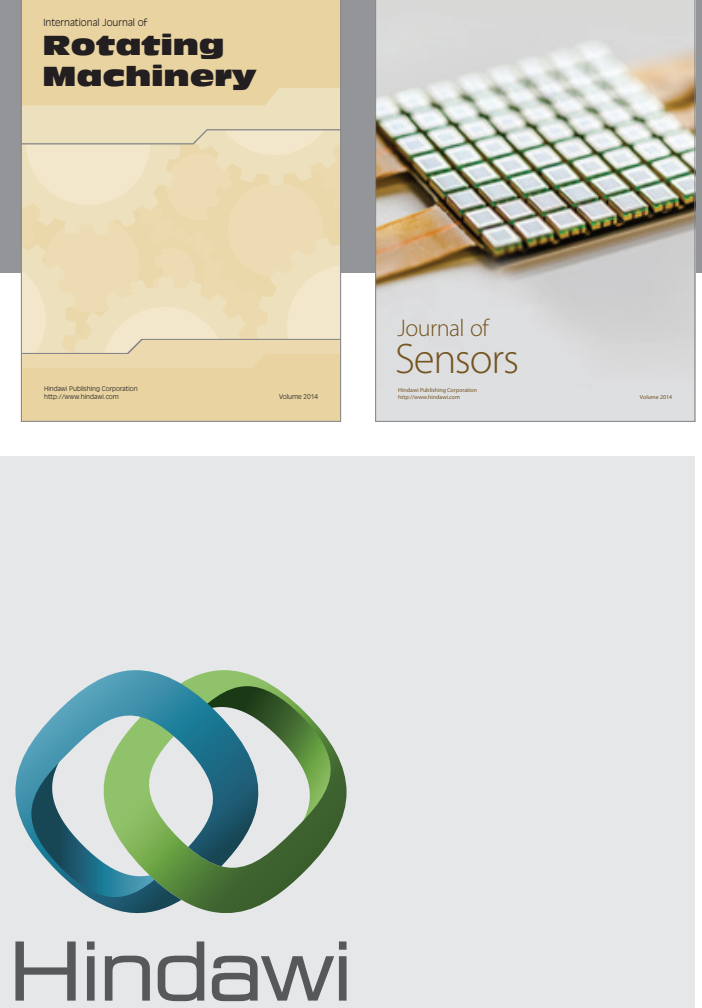

Submit your manuscripts at http://www.hindawi.com
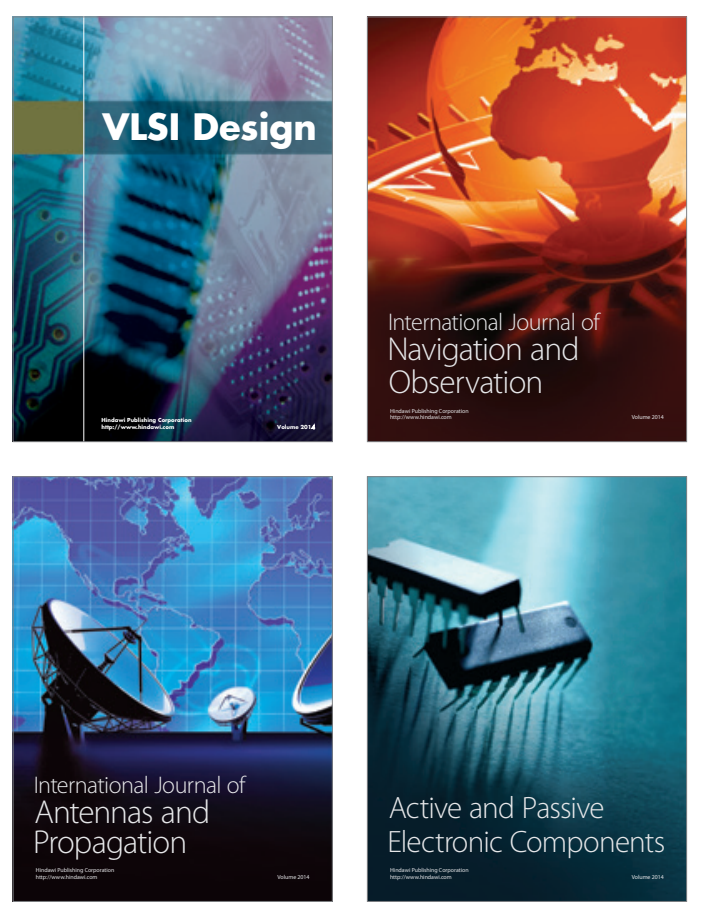
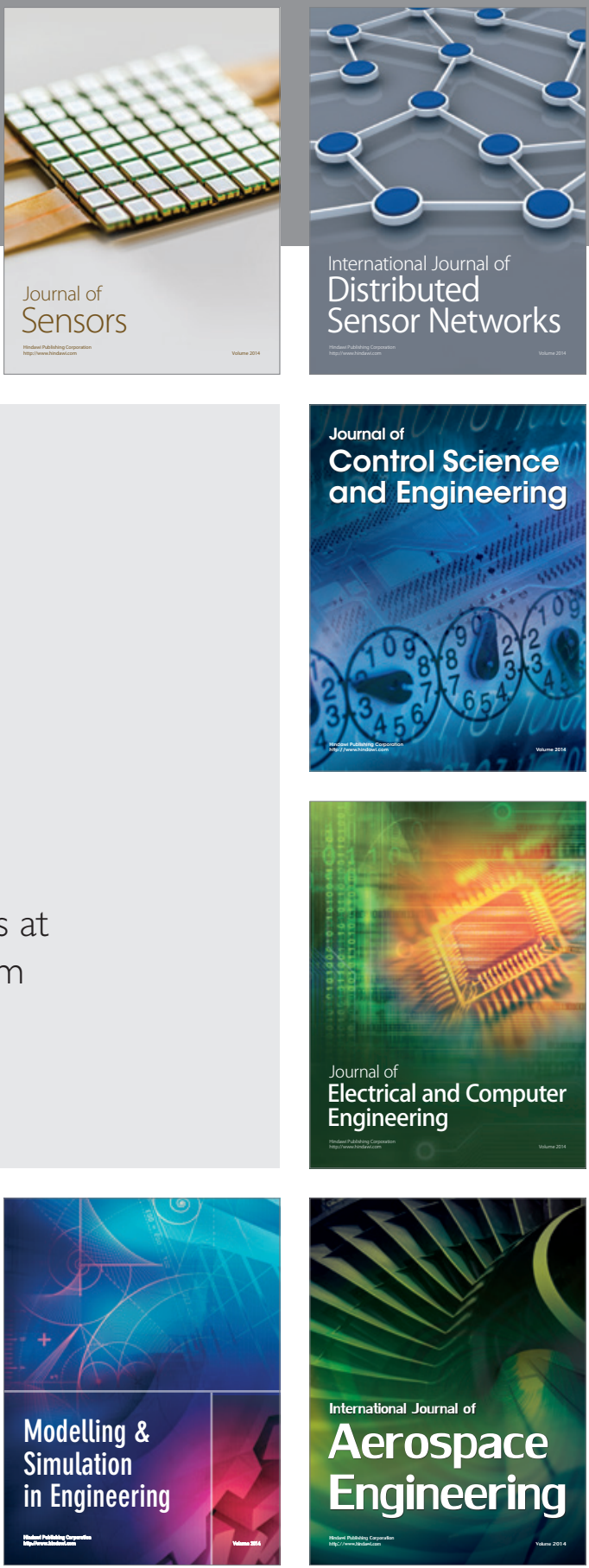

Journal of

Control Science

and Engineering
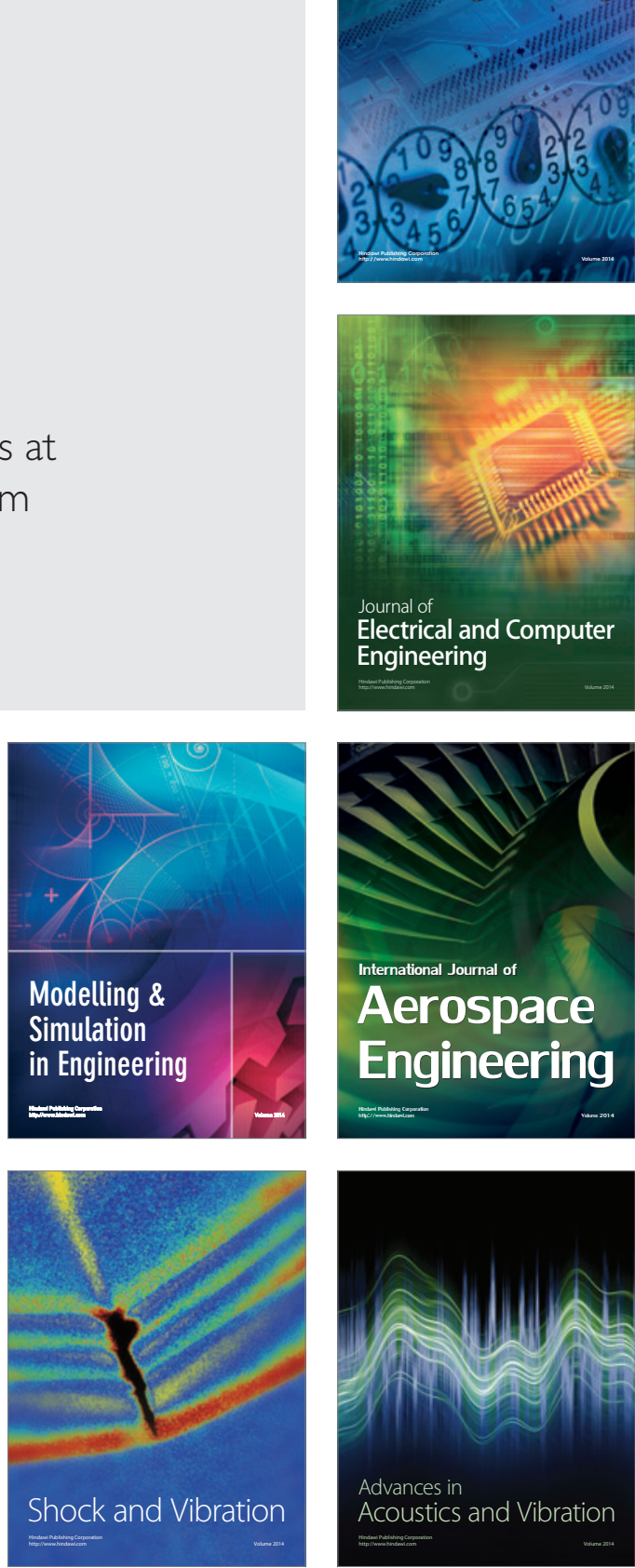